\title{
Acceptance, well-being, and goals in adolescents with chronic illness: a daily process
}

analysis

Annabelle Casier ${ }^{1, *}$, Liesbet Goubert ${ }^{2}$, Winifred A. Gebhardt ${ }^{3}$, Frans De Baets ${ }^{4}$, Sara Van Aken $^{5}$, Dirk Matthys ${ }^{6}, \&$ Geert Crombez ${ }^{7}$

1 Department of Experimental-Clinical and Health Psychology, Ghent University, Henri Dunantlaan 2, 9000 Ghent, Belgium. Tel: +32 (0)9 26491 06. E-mail:

Annabelle.Casier@ugent.be

2 Department of Experimental-Clinical and Health Psychology, Ghent University, Henri Dunantlaan 2, 9000 Ghent, Belgium. Tel: +32 (0)9 26462 62. E-mail:

\section{Liesbet.Goubert@ugent.be}

3 Leiden University, Clinical- Health and Neuropsychology, Leiden University, Wassenaarseweg 52, 2333 AK Leiden, The Netherlands. Tel: +31 (0)71 527 4084. E-mail: gebhardt@fsw.leidenuniv.nl

4 Department of Pediatrics and Medical Genetics, University Hospital Ghent, De Pintelaan 185, 9000 Ghent, Belgium. Tel: +32 (0)9 33235 86. E-mail: Frans.Debaets@ugent.be

5 Department of Pediatrics and Medical Genetics, University Hospital Ghent, De Pintelaan 185, 9000 Ghent, Belgium. Tel: +32 (0)9 33264 67. E-mail: Sara.Vanaken@ugent.be

6 Department of Pediatrics and Medical Genetics, University Hospital Ghent, De Pintelaan 185, 9000 Ghent, Belgium. Tel: +32 (0)9 33235 84. E-mail: Dirk.Matthys@ugent.be

7 Department of Experimental-Clinical and Health Psychology, Ghent University, Henri Dunantlaan 2, 9000 Ghent, Belgium. Tel: +32 (0)9 26464 61. E-mail:

Geert.Crombez@ugent.be

* Corresponding author

Number of words: 6927 
Running head: ACCEPTANCE, WELL-BEING, GOALS IN CHRONIC ILLNESS

\begin{abstract}
Objective: The main aim of this study was to investigate the relationship between acceptance and well-being in adolescents with chronic illness from a daily process perspective. Furthermore, we explored the role of daily experienced interference and facilitation of life goals by treatment goals as mediating mechanisms.

Methods: Thirty-eight adolescents with cystic fibrosis or diabetes completed questionnaires assessing acceptance, negative life events and goal-related self-efficacy. Furthermore, an online diary assessing daily mood, daily experienced interference and facilitation of life goals by treatment goals was completed during three consecutive weeks.

Results: Acceptance of illness was positively related to daily well-being, but unrelated to daily goal interference and facilitation. Furthermore, daily goal interference and facilitation were unrelated to same and next day well-being.

Conclusion: This study suggests that acceptance of illness plays an important role in the daily mood of adolescents with cystic fibrosis and diabetes. This relationship, however, was not mediated by daily experienced interference and facilitation of life goals by treatment goals. Further research is needed to determine whether interventions promoting acceptance are beneficial for adolescents with cystic fibrosis and diabetes. Keywords: acceptance, well-being, chronic illness, goal interference, goal facilitation
\end{abstract}


Running head: ACCEPTANCE, WELL-BEING, GOALS IN CHRONIC ILLNESS

\section{Acceptance, well-being, and goals in adolescents with chronic illness}

Previous research has indicated that growing up with chronic illness is a risk factor for several problems such as depressive symptoms, behaviour problems, and impairment in academic, physical, and social functioning. However, not all adolescents with chronic illness seem to struggle to maintain high well-being (see Pinquart \& Shen, 2011; Pinquart \& Teubert, 2012). Hence, investigating the factors influencing well-being in adolescents with chronic illness is of great importance.

In the context of chronic illness, it has been suggested that the way in which affected individuals evaluate their illness plays an important role in their well-being (Evers et al., 2001; Maes \& Karoly, 2005). A specific type of evaluation that may be relevant is 'acceptance'. Acceptance can be defined as 'recognizing the need to adapt to chronic illness while perceiving the ability to tolerate the unpredictable, uncontrollable nature of the disease and handle its averse consequences' (Evers et al., 2001, p. 1027). Questionnaire studies have shown that acceptance may have a protective role in the well-being of adolescents with illnesses such as chronic pain (e.g., McCracken, Gauntlett-Gilbert, \& Eccleston, 2010; Wicksell, Olssen, \& Hayes, 2011), juvenile arthritis (Feinstein et al., 2011), sickle cell disease (Masuda, Cohen, Wicksell, Kemani, \& Johnson, 2011), and cystic fibrosis (e.g., Casier et al., 2011). Specifically, this research has shown that higher acceptance of chronic illness is related to positive outcomes such as less anxiety, less depression, less disability, and better emotional, social, and physical functioning. The present study will contribute to this literature by examining whether acceptance of illness also plays a role in the (fluctuations in) daily well-being (i.e., positive/negative mood) of affected adolescents.

As yet, no research has addressed the processes underlying the relationship between acceptance and well-being. As chronic illness creates the need to pursue additional treatment goals to keep an optimal level of physical functioning and well-being, the experience of 
interference and/or facilitation of life goals (e.g., academic performance) by these treatment goals may be potential candidates. Goal interference occurs when striving for one goal (e.g., adhering to treatment) decreases the chance of attaining another goal (e.g., becoming independent) and can arise from limited resources for goal striving (e.g., time, energy) and/or from incompatible goal striving strategies (Little, 1983; Riediger \& Freund, 2004). Goal facilitation occurs when striving for one goal increases the chance of attaining another goal (e.g., the goal 'doing treatment' may facilitate the goal 'improving the relationship with my parents' as it may lead to less tension between adolescents and their parents). Reasons for investigating goal interference and facilitation as possible underlying mechanisms in the relationship between acceptance and well-being are twofold. First, acceptance is assumed as having a key role in the pursuit of important life goals despite being ill (Evers et al., 2001; Hayes, Luoma, Bond, Masuda, Lillis, 2006; Maes \& Karoly, 2005; Risdon, Eccleston, Crombez, \& McCracken, 2003). Therefore, acceptance may also relate to the extent to which goals interfere with and/or facilitate each other during their pursuit. Second, goal processes have increasingly been suggested as impacting well-being in the context of chronic illness (De Ridder \& Kuijer, 2007; Gebhardt, 2008). Indeed, previous research in healthy individuals has shown that goal interference is related to lower levels of well-being, whereas goal facilitation is mostly unrelated, but sometimes positively related to well-being (see Riediger, 2007 for an overview). If this is also the case in individuals with chronic illness is not yet known and has to be empirically investigated. Insight in how acceptance impacts well-being, and whether acceptance impacts well-being through intergoal interference/facilitation is particularly relevant in adolescence since achieving important life goals in the transition to adulthood may be more difficult for adolescents with chronic illness than for healthy peers (Badlan, 2006; Schwartz \& Drotar, 2006). 


\section{Running head: ACCEPTANCE, WELL-BEING, GOALS IN CHRONIC ILLNESS}

The primary aim of the present study was to examine the relationship between acceptance and well-being (i.e., daily mood) in adolescents with chronic illness on a daily basis. The secondary aim was to investigate whether acceptance was related to daily goal interference and facilitation, whether daily goal interference/facilitation was related to wellbeing, and whether the relationship between acceptance and daily well-being was mediated by goal interference/facilitation. Thirty-eight adolescents with chronic illness reported on daily well-being (i.e., positive/negative mood), daily experienced interference and facilitation of life goals by treatment goals. A daily process perspective allows investigating the experiences of adolescents in their natural context, capturing experiences closely to their occurrence, and reducing the chance of recall bias (Bolger, Davis, \& Rafaeli, 2003). It was hypothesized that higher levels of acceptance are related to higher daily positive mood, lower daily negative mood, and to less experienced interference in daily life goals. Furthermore, we expected higher experienced interference in daily life goals to be related to lower (same and next day) positive mood and higher (same and next day) negative mood. Same and next day mood were both included to examine whether interference has immediate or longer term effects. Finally, the relationships among acceptance, goal facilitation and daily mood were explored, as well as the mediating role of goal interference and facilitation in the relationship between acceptance and daily mood. Given the inconsistency and/or absence of previous findings concerning goal facilitation and same and next day mood, no explicit hypotheses about the relationships including goal facilitation and same and next day mood were formulated. We controlled for age, gender, and disease-related variables given their potential impact upon goals and wellbeing (e.g., Massey, Gebhardt, \& Garnefski, 2008). Furthermore, in line with recommendations from previous research and theory on goals, we controlled for goal-related self-efficacy and negative life events when testing the hypotheses with goal interference and facilitation as outcomes. Indeed, goal-related self-efficacy has shown to play a role in goal 
setting and striving, whereas negative life events may radically change the setting of and striving for goals (e.g., Brandtstädter \& Renner, 1990; Massey et al., 2008; Schwartz \& Drotar, 2009).

\section{Method}

This study is part of the Goals, Acceptance, and Well-being in Chronic Illness (GAWCI) study, performed between September 2010 and April 2012 in Flanders, Belgium. Participants for the GAWCI study were adolescents with cystic fibrosis (CF) and diabetes and matched (age and gender) healthy peers. The healthy peers (recruited from a sample of school children who participated between 2008 and 2011 in one of two questionnaire studies, see Caes, Vervoort, Eccleston, \& Goubert, in revision and Vervoort, Huguet, Verhoeven, \& Goubert, 2011, and had given consent to be re-contacted for other studies) were included in an independent part of the GAWCI study not reported here. To recruit the adolescents with CF all four Flemish University Hospitals were contacted for participation. The University Hospitals of Ghent and Leuven agreed to take part in the study. To recruit the adolescents with diabetes, the University Hospital of Ghent was contacted and agreed to participate.

\section{Participants}

Inclusion criteria for individual participation were: 14-22 years of age, comprehension of the Dutch language, and no developmental disorder. Furthermore, adolescents with CF who had/were awaiting lung transplantation were excluded because of the exceptional status of this situation (e.g., very high level of symptoms, being terminally ill, intertwinement of end of life issues and hope of transplantation) (Bourke et al., 2009). One hundred and thirty adolescents, of whom 74 had CF and 56 had diabetes, met the inclusion criteria. All eligible participants were invited by letter and/or recruited during routine clinic visits by the psychologist from the respective hospital (time period of recruitment: September 2010-April 2011). Subsequently, adolescents who agreed to participate $(N=82)$ where phoned by a research assistant and a 
home visit was planned. Finally, 62 adolescents ( 27 males, 35 females; response rate $=$ $47.69 \%$ ) with CF and diabetes took part in the GAWCI study. The main reasons for not participating were a lack of time and interest. Of the 62 adolescents enrolled in the study, 58 agreed to complete the diary. In case less than $75 \%$ of the requested diaries were completed, data were excluded from further analysis (Huijnen, Verbunt, Roelofs, Goossens, \& Peters, 2009), resulting in a final sample of 38 adolescents (participation rate $=29 \%$; $\mathrm{CF}: N=22,12$ males, 10 females; diabetes: $N=16,6$ males, 10 females). All adolescents were of Caucasian origin. Mean age was 18.63 years $(S D=2.75)$ for the adolescents with $\mathrm{CF}$ and 16.30 years $(S D=1.58)$ for the adolescents with diabetes. Mean time since diagnosis was 16.28 years $(S D$ $=5.83)$ for the adolescents with $\mathrm{CF}$, and 8.07 years $(S D=4.46)$ for the adolescents with diabetes. $T$-tests revealed that, in comparison with adolescents with diabetes, adolescents with CF were significantly older $\left(M_{c}=18.63, S D_{c}=2.75 ; M_{d}=16.30, S D_{d}=1.58 ; t=3.30, p<\right.$ .01). All adolescents were going to school at the time of participation. Of the nonparticipants, $56.52 \%$ was diagnosed with $\mathrm{CF}$ and $43.48 \%$ with diabetes. Because of confidentiality, no further data about the characteristics of the non-participants were available.

\section{Procedure}

First, a research assistant visited the participants at home. During this visit, written parent consent (adolescents $<18$ years) and/or adolescent assent (adolescents $<18$ years)/consent (adolescents > 18 years) were obtained and a set of questionnaires was completed under supervision of a research assistant. Of this set, only the questionnaires concerning goal content, acceptance of illness, negative life events, and goal-related selfefficacy were included in the present study. At the end of this home visit the research assistant explained the diary procedure. After the home visit, each participant's self-generated most important goals were entered in a personal online diary created with LimeSurvey 1.85 software. Then, each adolescent received an e-mail containing a link to their personal diary 
accompanied by explicit guidelines on how to complete it. In this diary, daily experienced interference and facilitation of personal goals by treatment goals were assessed during three consecutive weeks, along with daily mood and the extent to which goal pursuit was hindered by daily physical complaints. For the present study, only the diary questions on goal interference and facilitation and daily mood were used. Additional paper versions of the diary, to be used in case of computer or internet problems, were sent by regular mail. Participants were instructed to complete the diary at the end of the day. To reduce the number of missing data to a minimum every participant daily received a reminding text message (SMS) at 7.00 p.m. All participants received a financial compensation of $€ 30$ for computer and internet use. The ethical committees of the University Hospitals of Ghent and Leuven approved the GAWCI study.

\section{Measures}

\section{Questionnaires}

Socio-demographic information (age, gender, time since diagnosis, type of diagnosis) was verbally inquired before administration of the questionnaires.

Acceptance was assessed by a subscale of the Dutch version of the Illness Cognition Questionnaire (ICQ; Evers et al., 2001). Acceptance is conceptualised as the perceived ability to live with the illness and to master its negative consequences ( six items, e.g. "I can handle the problems related to my illness"). Items are rated on a 4-point Likert scale ( $1=$ not at all, 4 = completely). The total score for acceptance varies between 6 and 24, with higher scores indicating higher levels of acceptance. Psychometric research in samples of Dutch-speaking adults with rheumatoid arthritis, multiple sclerosis, chronic pain and chronic fatigue demonstrated the adequate reliability and validity of the ICQ (Evers et al., 2001; Lauwerier et al., 2010). Reliability of the acceptance scale in the research sample of the present study was good with a Cronbach's $\alpha$ of .82. 


\section{Running head: ACCEPTANCE, WELL-BEING, GOALS IN CHRONIC ILLNESS}

Goals were explored using an open goal-elicitation procedure. To ensure that several domains of life were considered during this elicitation, all adolescents were asked to report their goals for the following five domains: school/work, relationships, leisure time, yourself (personal development), and health/body. This categorization of goal domains was used as it is consistently supported by earlier goal research in adolescents (for a review see Massey et al., 2008). Goals were generated by the adolescents themselves instead of externally determined, what made it personally relevant. Adolescents were free to report as many goals as they wanted. Following Massey and colleagues (2009a), goals were elicited by means of the following instruction: 'Some things you find important in life, other things you find less important. People differ in this respect: what one considers important and consequently has as a goal, can be less important for another. Everyone has his or her own goals, and that makes every person unique and special. Some goals you like to attain, other goals matter less. We would like to ask you some questions concerning the things you consider important in life. In other words: what are your most important goals? It is important to know that : (a) one can have different goals in different domains at the same time, for example in the domain of school, relationships, work, yourself, leisure time, or health, (b) goals have to do with either wanting to do something or exactly not wanting to do it. We are interested in the goals that you are currently pursuing, and that will still be important for you within a few months.'. After the elicitation procedure, all adolescents were asked to select their most important goal per domain, except for the health domain. As the current study focused on the interrelationship of personal goals with treatment goals, the goal 'doing my treatment' was fixed as most important within this domain. This procedure was pilot tested on comprehensibility and relevance in eight healthy adolescents. As this pilot test was successful, no modifications to the original procedure were made. 


\section{Running head: ACCEPTANCE, WELL-BEING, GOALS IN CHRONIC ILLNESS}

Negative life events were measured by using a 12-item lifetime checklist for adolescents adapted from Kraaij et al. (2003). This checklist measures negative life events concerning self or significant others during the past year, such as death of someone close, parental divorce, and abuse experiences. Sum scores are computed by adding up all negative life events experienced throughout life (range 0-12).

Goal-related self-efficacy refers to the perception of self-efficacy in relation to being able to achieve one's goals despite possible obstacles and was measured by an adaptation of Schwarzer's General Self-Efficacy Scale (see Massey et al., 2009a). The scale consists of 10 items (e.g., "I can always manage to achieve my goals if I try hard enough") and is rated on a 4-point Likert scale $(1=$ not at all true, $4=$ exactly true $)$. A mean score of these 10 items was calculated (range 1-4), with higher scores indicating more goal related self-efficacy. Reliability in the present study was good with a Cronbach's $\alpha$ of .80 .

Health status was subjectively rated on a 5-point Likert scale ("How would you describe your current health status?"; $1=b a d, 5=$ excellent ). Diary

Daily mood was assessed with the Brief Mood Rating Scale (Diener \& Emmons, 1985). This nine-item scale measures positive (four items, e.g., "happy”, “joyful”, “enjoyment/fun”, "pleased”) and negative mood (five items, e.g., "depressed/blue”, “unhappy”, “frustrated”, “angry/hostile”, “worried/anxious”). Items are rated on a 7-point Likert scale $(0=$ not at all, $6=$ extremely much $)$. Total scores range from 0 to 24 for positive mood and from 0 to 30 for negative mood, with higher scores indicating higher positive, respectively negative mood. The scale has been reported to have good reliability and validity properties (Diener \& Emmons, 1985). Cronbach's $\alpha$ in the current sample was .98 for positive and .90 for negative mood. 


\section{Running head: ACCEPTANCE, WELL-BEING, GOALS IN CHRONIC ILLNESS}

Goal facilitation and interference were measured with an adapted version of Little's Personal Projects Cross-Impact Matrix

(http://www.brianrlittle.com/Topics/research/assessment-tools/). All adolescents were requested to rate to what extent their health/body goal, that was fixed as 'doing my treatment', had a positive/negative influence on their most important school/work, relationships, free time, and yourself goal. All items were rated on an 11-point Likert scale $(0=n o$ positive/negative influence, $10=$ strong positive/negative influence), with higher scores indicating a more positive/negative influence. A mean score of these four items was calculated. The adapted matrix was successfully tested on comprehensibility and relevance in a pilot study with eight healthy adolescents.

\section{Data analysis}

The current data had a multilevel structure as the daily reports (level 1) were hierarchically nested within the participating individuals (level 2). The level 1 variables consisted of the daily observations of positive and negative mood, goal facilitation and goal interference ( 21 days), whereas the level 2 variables consisted of the between-person variables gender (dummy coded: $0=$ male, $1=$ female), age, time since diagnosis, type of diagnosis (dummy coded: $0=$ cystic fibrosis, $1=$ diabetes), negative life events, goal-related selfefficacy, and acceptance (38 persons). Because of the hierarchical structure, a series of multilevel regression analyses using Hierarchical Linear Modelling (HLM 6.0 software package) was performed.

Before testing the hypotheses, baseline models without any predictors were run for each (same and next day) dependent variable to calculate the amount of within (level 1) and between person (level 2) variance. To test the hypotheses including predictions over time (i.e., interference/facilitation and next day mood), variables with lags of one day $(n-1)$ were created for daily goal interference and facilitation. To explore whether the relationship between 
Running head: ACCEPTANCE, WELL-BEING, GOALS IN CHRONIC ILLNESS

acceptance and daily mood is explained by goal interference and facilitation the procedure for investigating mediation described in Nezlek (2011) was followed.

As recommended by Nezlek (2011), all level 1 variables were entered group mean centered. Level 2 variables were entered grand mean centered, except for the categorical variables, which were entered uncentered. This way of centering is closest to group regression analyses and helps interpreting the intercept (see Nezlek, 2011 for further statistical information). A random error term was estimated for each level 1 variable. Full maximum likelihood estimation was used for all analyses. Associated effect-size correlations (see Rosenthal \& Rosnow, 1991, p. 441) were estimated for each set of multilevel regression analyses, with $r=.10$ indicating a small effect size, $r=.30$ indicating a medium effect size, and $r=.50$ indicating a large effect size (Cohen, 1992).

\section{Results}

\section{Aggregated data}

Diary data were available for 38 adolescents. A total of 737 days were completed out of a possible 798 days (completion rate $=92.36 \%$ ). As presented in Table 1 , mean score for acceptance was $19.32(S D=3.04)$, which is in line with previous research in adolescents with CF (Casier et al., 2011). Adolescents reported on average 1.11 negative life events during the past year $(S D=1.09)$. Mean goal-related self-efficacy was $3.08(S D=.34)$. Mean positive mood was $16.65\left(M_{C F}=17.62 ; M_{d i a}=15.35\right)$, whereas mean negative mood was $3.72\left(M_{C F}=\right.$ $2.87 ; M_{\text {dia }}=4.85$ ), which seems to be in line with previous research in adolescents with $\mathrm{CF}$ and diabetes (e.g., Casier et al., 2011; De Wit et al., 2010). The mean for goal facilitation was $9.53(S D=7.05)$ and $2.71(S D=4.01)$ for goal interference. $T$-tests revealed that, in comparison with adolescents with diabetes, adolescents with CF had a significant longer time since diagnosis, a higher positive mood, a lower negative mood, and less goal facilitation. No significant differences between adolescents with cystic fibrosis and diabetes were found in 
health status, negative life events, goal-related self-efficacy, acceptance, and goal interference (see Table 1). Examples of frequently reported goals were 'getting good grades', 'exercise more', and 'spending more time with friends'.

\section{-INSERT TABLE 1 ABOUT HERE-}

\section{Multilevel data}

The role of acceptance in daily mood

Forty-two per cent of the variance in negative mood was due to variation between adolescents (level 2) and 58\% to variation within adolescents (level 1). Fifty-two per cent of the variance in positive mood was due to variation between adolescents (level 2) and $48 \%$ to variation within adolescents (level 1). In line with expectations, acceptance was negatively related to negative $\operatorname{mood}\left(\beta_{06}=-.34, t(30)=-2.49, p=.02, r=.32\right)$ and positively related to positive $\operatorname{mood}\left(\beta_{06}=.55, t(30)=4.73, p=.00, r=.53\right)$. Of the control variables, time since diagnosis and type of diagnosis were significantly related to negative mood, and type of diagnosis also to positive mood (see Table 2). The longer the time since diagnosis, the more negative mood was reported. Furthermore, adolescents with diabetes reported on average higher levels of negative mood and lower levels of positive mood than adolescents with cystic fibrosis.

\section{-INSERT TABLE 2 ABOUT HERE-}

The role of acceptance in daily goal interference and facilitation

Fifty-nine per cent of the variance in goal interference was due to variation between adolescents (level 2) and $41 \%$ to variation within adolescents (level 1). Eighty-five per cent of the variance in goal facilitation was due to variation between adolescents (level 2) and 15\% to variation within adolescents (level 1). Multilevel analyses (see Table 3) revealed that acceptance of illness was not related to experienced interference of life goals by treatment goals $\left(\beta_{08}=-.22, t(27)=-1.36, n s, r=.20\right)$, nor to facilitation of life goals by treatment goals 
Running head: ACCEPTANCE, WELL-BEING, GOALS IN CHRONIC ILLNESS

$\left(\beta_{08}=-.51, t(24)=-1.28, n s, r=.20\right)$. None of the control variables (gender, age, time since diagnosis, type of diagnosis, health status, negative life events, and goal-related self-efficacy) were related to goal interference and facilitation.

\section{-INSERT TABLE 3 ABOUT HERE-}

\section{The role of goal interference and facilitation in daily mood}

Contrary to expectations (see Tables 4 and 5), higher experienced interference of life goals by treatment goals was unrelated to same day negative mood $\left(\beta_{10}=.12, t(35)=1.52, n s\right.$, $r=.19)$, same day positive $\operatorname{mood}\left(\beta_{10}=-.05, t(35)=-.60, n s, r=.06\right)$, next day negative mood $\left(\beta_{10}=.02, t(35)=.27, n s, r=.03\right)$ and next day positive $\operatorname{mood}\left(\beta_{10}=-.04, t(35)=-.48, n s, r=\right.$ .06). Facilitation of life goals by treatment goals was unrelated to same day negative mood $\left(\beta_{10}=-.10, t(32)=-.96, n s, r=.12\right)$, same day positive $\operatorname{mood}\left(\beta_{10}=.16, t(32)=1.92, n s, r=\right.$ $.22)$, next day negative mood $\left(\beta_{10}=-.04, t(32)=-.45, n s, r=.06\right)$ and next day positive mood $\left(\beta_{10}=.08, t(32)=1.00, n s, r=.12\right)$. Of the control variables type of diagnosis and time since diagnosis were significantly related to negative mood (see Table 3 and 4). Having diabetes and a longer time since diagnosis were associated with higher levels of negative mood. Furthermore, age, type of diagnosis, and health status were significantly related to positive mood (see Table 3 and 4). This indicated that a higher age, having diabetes, and a worse health status were related to lower levels of positive mood.

\section{-INSERT TABLE 4 ABOUT HERE- -INSERT TABLE 5 ABOUT HERE-}

As the relationships between acceptance and goal interference/facilitation and between goal interference/facilitation and well-being were not significant, no further testing for a mediational effect was performed.

\section{Discussion}




\section{Running head: ACCEPTANCE, WELL-BEING, GOALS IN CHRONIC ILLNESS}

To our knowledge, this is the first study using a daily diary approach for investigating the relationships between acceptance, daily well-being, goal interference and facilitation by treatment goals in adolescents with chronic illness. Advantages of this approach are the investigation of experiences in their natural context and closely to their occurrence (Bolger et al., 2003). Furthermore, the current focus on daily well-being (i.e. mood) as an outcome is of great importance in the context of chronic illness. Mood indeed has the potential to influence one's immune system as well as for example treatment adherence, and consequently also health (see Antoni, 2012 and DiMatteo, Lepper, \& Croghan, 2000 for an overview).

In line with previous research in adolescents with chronic illness (e.g., Casier et al., 2011), higher levels of acceptance were found to relate to better daily well-being (i.e. mood). This study extends previous research by its focus on daily processes and by incorporating mood as outcome. This established relationship indeed conforms the description of acceptance as the strength to focus on what is pleasurable in life despite being ill. It is seen as a method to increase action toward what is valued in life, and not as a sign of weakness, resignation, and failure, (Evers et al., 2001; Hayes et al., 2006; Risdon et al., 2003). By doing so, a meaningful life and well-being can be sustained (Hayes et al., 2006), which is supported by the current results.

This study also, for the first time, investigated the relationship between acceptance and goal processes such as the experience of interference (when striving for one goal decreases the chance of attaining another goal) or facilitation (when striving for one goal increases the chance of attaining another goal) between goals. Contrary to our expectations, acceptance was not related to any of these experiences. Possible explanation for this lack of findings is that acceptance of illness may not relate to the experience of goal interference and facilitation per se, but rather to the way one deals with these experiences. This explanation is in line with the conceptualisation of acceptance, defined in terms of "adapting to chronic illness" and 
"handling averse consequences"' (Evers et al., 2001, p. 1027). It suggests that acceptance may rather be associated with other goal-related constructs such as a balance between treatment goals and other important life goals, the relative importance of these goals, and the amount of success in the pursuit of these goals. Acceptance indeed includes an engagement in important life goals despite being ill (Evers et al., 2001; Hayes et al., 2006). This may mean that a balanced interplay between treatment goals (e.g., doing treatment) and other important life goals (e.g., building social relationships, getting an academic degree, becoming independent) is essential. Future research should investigate if acceptance indeed relates to these constructs and experiences.

Furthermore, the current findings revealed that the previously established relationship between goal interference and well-being (for an overview see Riediger, 2007) has not been confirmed in the context of chronic illness and/or when studied from a daily process perspective. Several explanations can be proposed for these unexpected results. First of all, goal interference may not have instant but rather long-term effects on well-being (Boersma, Maes, \& van Elderen, 2005). The present study does not allow conclusions about possible long-term effects. Future research should therefore investigate this association within a broader time frame (e.g., weeks or months instead of days). Second, it is possible that goal interference may only relate to daily well-being in a subsample. Given that (a) adolescents with diabetes reported worse mood but equal levels of goal interference compared to adolescents with $\mathrm{CF}$ and (b) adolescents with $\mathrm{CF}$, compared to adolescents with diabetes, already had more time to find a way to deal with the experience of goal interference (i.e., longer time since diagnosis), it is possible that the type of diagnosis moderates the relationship between goal interference and daily well-being. Further research using larger samples is needed to investigate this hypothesis. Ways of handling the experience of goal interference may include a search for compatible strategies to attain different goals, the 
identification of possible instrumental relations between goals, the optimisation of the use of limited resources (e.g., time, energy), the search for other goals in the same domain or alternative routes to goals, scaling back goals, or even the disengagement from incompatible and reengagement in other compatible goals (e.g., choosing home-based instead of outdoor leisure activities that can be performed during aerosol treatment). Third, not the experience of goal interference itself, but rather the emotional reactions arising from this interference may affect well-being. This explanation is in line with recent research suggesting that not the actual number of blocked goals but the frustration arising from it relates to well-being (Massey et al., 2009a; Massey, Garnefski, Gebhardt, \& van der Leeden, 2009b). Fourth, the current study fixed the treatment goal of the participating adolescents as 'doing treatment'. This goal may have been formulated too general and comprehensive. Further research focussing on specific aspects of treatment that adolescents identify as very important is needed.

Next to focussing on goal interference, this study also, as a first, explored the relationship between goal facilitation and well-being in the context of chronic illness. Previous research on goal facilitation revealed mixed results, with facilitation predominantly being unrelated, but sometimes positively related to well-being (Riediger, 2007; Riediger \& Freund, 2004). The current results support the findings that goal facilitation by treatment goals is unrelated to daily mood. This indicates that the degree to which the pursuit of treatment goals makes the pursuit of other valued goals easier does not relate to the degree of negative and positive mood in adolescents with $\mathrm{CF}$ and diabetes. That goal facilitation did not relate to mood may be explained by the fact that individuals generally do not react strongly to gains (see Riediger, 2007). For future research, comparing experienced goal interference and facilitation between individuals with chronic illness and healthy peers may be interesting. 
Running head: ACCEPTANCE, WELL-BEING, GOALS IN CHRONIC ILLNESS

This kind of research may clarify whether it is essential to further address goal interference in chronically ill adolescents, and may offer important starting points for intervention.

Some limitations of this study should be mentioned. First, the current sample reported on average rather high levels of acceptance and positive mood, and low levels of goal interference and negative mood. Therefore, it is uncertain whether the current findings are generalizable to adolescents reporting lower levels of acceptance and daily well-being, and higher levels of goal interference. Second, the current study only relied on self-report measures. A multi-method approach including reports of other informants such as parents and caregivers, would contribute to the strength of the current findings. Third, acceptance was assessed with only one scale. There is a need for more instruments assessing acceptance in the context of chronic illness. These instruments should not only focus on dealing with uncontrollability, unpredictability, and negative consequences of being ill, but should also address other aspects of acceptance such as dealing with unwanted thoughts and feelings and engaging in activities that serve important life goals despite being ill (Casier et al., 2011). A starting point for the development of these instruments could be the Acceptance and Action Questionnaire (AAQ; Hayes et al., 2004). Fourth, the current results should be interpreted with caution as the response rate was rather low. It is possible that participating adolescents had particular characteristics that do not generalize to non-participating adolescents (e.g., better health status). Fifth, data of adolescents with CF and diabetes were not analysed separately because of the limited number of participants. Consequently, it is not known whether the current results also apply to samples consisting exclusively of adolescents with $\mathrm{CF}$ or diabetes (i.e., differences in treatment, symptoms, etc.). Future research, including larger samples is needed to conduct separate analyses for both groups. Sixth, due to the lack of adolescents with other chronic conditions, the current results are not generalizable beyond $\mathrm{CF}$ and diabetes. Further research on goals and acceptance should include more diverse 
samples of affected adolescents. By doing this, findings applying across conditions can be identified. Also, the current sample consisted of adolescents with a wide age range (14-22 years). Although age was not related to the outcomes studied, it is still possible that age differences in these outcomes were not detected. For example, it may be that older adolescents experience goal interference and facilitation differently from younger adolescents given their greater autonomy in goal setting and striving. Also, it is possible that acceptance of illness is interpreted differently by older adolescents compared to younger ones given their growing understanding of their illness and its implications (Massey et al., 2008; Schwartz \& Drotar, 2009).

The findings from the current study suggest important target points for intervention in adolescents with chronic illness. As acceptance relates to daily well-being, adolescents with chronic illness may benefit from psychological interventions to promote acceptance. Approaches addressing acceptance, such as Acceptance and Commitment Therapy (ACT; Hayes, 2004) already exist for several paediatric chronic conditions (e.g., sickle cell disease, chronic pain) and demonstrate promising results (e.g., Masuda et al., 2011; Wicksell et al., 2009). Further research into the factors that may relate to and influence acceptance is needed to determine if these interventions are useful for adolescents with $\mathrm{CF}$ and diabetes. If acceptance indeed seems to be a workable key factor in the well-being of these adolescents, existing interventions such as ACT (Hayes, 2004) could be modified for and tested in the context of cystic fibrosis and diabetes.

\section{Acknowledgements}

The authors want to thank all adolescents and their parents for their cooperation in this study, Emma Massey for her help with the diary development, Sien Lagae, Liese Aerts, Lieve DeSmet, and Astrid Dendauw for their help with data collection, and Thomas Onraedt for his help with LimeSurvey 1.85. Finally, we express our gratitude to Trudy Havermans, Marleen 
Running head: ACCEPTANCE, WELL-BEING, GOALS IN CHRONIC ILLNESS

Theunis, Heidi Vanden Bossche, and Jolien Laridaen, as co-investigators, for their help in the recruitment of adolescents. 
Running head: ACCEPTANCE, WELL-BEING, GOALS IN CHRONIC ILLNESS

\section{References}

Antoni, P.H. (2012). Stress management, PNI, and disease. In Segerstrom, S.C. (Ed.), The Oxford Handbook of Psychoneuroimmunology (pp. 385-420). Oxford University Press, Inc.: New York, NY.

Badlan, K. (2006). Young people living with cystic fibrosis: an insight into their subjective experience. Health and Social Care in the Community, 14, 264-270. doi:

10.1111/j.1365-2524.2006.00619.x

Boersma, S.N., Maes, S., \& van Elderen, T. (2005). Goal disturbance predicts health-related quality of life and depression 4 months after myocardial infarction. British Journal of Health Psychology, 10, 615-630. doi: 10.1348/135910705X52525

Bolger, N., Davis, A., \& Rafaeli, E. (2003). Diary methods: capturing life as it is. Annual Review of Psychology, 54, 579-616. doi: 10.1146/annurev.psy.54.101601.145030

Bourke, S. J., Doe, S. J., Gascoigne, A. D., Heslop, K., Fields, M., Reynolds, D., \& Mannix, K. (2009). An integrated model of provision of palliative care to patients with cystic fibrosis. Palliative Medicine, 23, 512-517. doi: 10.1177/0269216309106312

Brandtstädter, J. \& Renner, G. (1990). Tenacious goal pursuit and flexible goal adjustment: explication and age-related analysis of assimilative and accommodative strategies of coping. Psychology and Aging, 5, 58-67.

Casier, A., Goubert, L., Huse, D., Theunis, M., Franckx, H., Robberecht, E. Matthys, D., \& Crombez, G. (2011). Acceptance and well-being in adolescents and young adults with cystic fibrosis: a prospective study. Journal of Pediatric Psychology, 36, 476-487. doi: 10.1093/jpepsy/jsq111

Cohen, J. (1992). A power primer. Psychological Bulletin, 112, 155-159. 
Running head: ACCEPTANCE, WELL-BEING, GOALS IN CHRONIC ILLNESS

De Ridder, D., \& Kuijer, R. (2007). Reconsidering illness-related goals: is discrepancy resolved by confronting emotions? Psychology and Health, 22, 107-122. doi: $10.1080 / 14768320600603471$

De Wit, M., Delemarre-Van de Waal, H.A., Bokma, J.A., Haasnoot, K., Houdijk, M.C., Gemke, R.J., \& Snoek, F.J. (2010). Follow-up results on monitoring and discussong health-related quality of life in adolescent diabetes care: benefits do not sustain in routine practice. Pediatric Diabetes, 11, 175-181. doi: 10.1111/j.13995448.2009.00543.x

Diener, E., \& Emmons, R.A. (1985). The independence of positive and negative affect. Journal of Personality and Social Psychology, 47, 1105-1117.

DiMatteo, M.R., Lepper, H.S., \& Croghan, T.W. (2000). Depression is a risk factor for noncompliance with medical treatment: meta-analysis of the effects of anxiety and depression on patient adherence. Archives of Internal Medicine, 160, 20101-20107. doi: 10.1001/archinte.160.14.2101

Evers, A.W.M., Kraaimaat, F.W., van Langenveld, W., Jongen, P.J.H., Jacobs, J.W.G., \& Bijlsma, J.W.J. (2001). Beyond unfavourable thinking: the Illness Cognition Questionnaire for chronic diseases. Journal of Consulting and Clinical Psychology, 69, 1026-1036. doi: 10.1037//0022-006X.69.6.1026

Feinstein, A.B., Forman, E.M., Masuda, A., Cohen, L.L., Herbert, J.D., Moorthy, L.N., \& Goldsmith, D.P. (2011). Pain intensity, psychological inflexibility, and acceptance of pain as predictor of functioning in adolescents with juvenile idiopathic arthritis: a preliminary investigation. Journal of Clinical Psychology in Medical Settings, 18, 291-298. doi: 10.1007/s10880-011-9243-6 
Running head: ACCEPTANCE, WELL-BEING, GOALS IN CHRONIC ILLNESS

Glasscoe, C. A., \& Quittner, A. L. Psychological interventions for people with cystic fibrosis and their families. Cochrane Database of Systematic Reviews 2008, Issue 3. Art. No.: CD003148. doi: 10.1002/14651858.CD003148.pub2.

Gebhardt, W.A. (2008). On multiple goals and continuous conflict. The European Health Psychologist, 10, 25-28.

Hayes, S.C. (2004). Acceptance and commitment therapy, relational frame theory, and the third wave of behavioural and cognitive therapies. Behavior Therapy, 35, 639-665.

Hayes, S.C., Luoma, J.B., Bond, F.W., Masuda, A., \& Lillis, J. (2006). Acceptance and Commitment Therapy: model, processes and outcomes. Behaviour Research and Therapy, 44, 1-25. doi:10.1016/j.brat.2005.06.006

Huijnen, I.P.J., Verbunt, J.A., Roelofs, J., Goossens, M., \& Peters, M. (2009). The disabling role of fluctuations in physical activity in patients with chronic low back pain. European Journal of Pain, 13, 1076-1079. doi: 10.1016/j.ejpain.2008.12.008

Kraaij, V., Garnefski, N., de Wilde, E.J., Dijkstra, A., Gebhardt, W., Maes, S., \& ter Doest Laura (2003). Negative life events and depressive symptoms in late adolescence: bonding and cognitive coping as vulnerability factors? Journal of Youth and Adolescence, 32, 185-193.

Lauwerier, E., Crombez, G., Van Damme, S., Goubert, L., Vogelaers, D., \& Evers, A. W. M. (2010). The construct validity of the Illness Cognition Questionnaire: the robustness of the three-factor structure across patients with chronic pain and chronic fatigue. International Journal of Behavioral Medicine, 17, 90-96. doi: 10.1007/s12529-009$9059-\mathrm{Z}$

Little, B. R. (1983). Personal projects: A rationale and method for investigation. Environment and Behavior, 15, 273-309. 
Maes, S. \& Karoly, P. (2005). Self-regulation assessment and intervention in physical health and illness: a review. Applied Psychology: An International Review, 54, $267-299$.

Massey, E.K., Gebhardt, W.A., \& Garnefski, N. (2008). Adolescent goal content and pursuit: a review of the literature from the past 16 years. Developmental Review, 28, 421-460. doi: 10.1016/j.dr.2008.03.002

Massey, E.K., Gebhardt, W.A., \& Garnefski, N. (2009a). Self-generated goals and goal process appraisals: Relationships with sociodemographic factors and well-being. Journal of adolescence, 32, 501-518. doi: 10.1016/j.adolescence.2008.07.003

Massey, E.K., Garnefski, N., Gebhardt, W.A., \& van der Leeden, R. (2009b). Daily frustration, cognitive coping and coping efficacy in adolescent headache: a daily diary study. Headache, 49, 1198-1205. doi: 10.1111/j.1526-4610.2009.01492.x

Masuda, A., Cohen, L.L., Wicksell, R.K., Kemani, M.K., \& Johnson, A. (2011). A case study: acceptance and commitment therapy for pediatric sickle cell disease. Journal of pediatric Psychology, 36, 398-408. doi: 10.1093/jpepsy/jsq118

McCracken, L.M., Gauntlett-Gilbert, J., \& Eccleston, C. (2010). Acceptance of pain in adolescents with chronic pain: validation of an adapted assessment instrument and preliminary correlation analyses. European Journal of Pain, 14, 316-320. doi: 10.1016/j.ejpain.2009.05.002

Nezlek, J.B. (2011). Multilevel Modelling for Social and Personality Psychology. London, UK: Sage Publications Ltd.

Pinquart, M., \& Shen, Y. (2011). Behavior problems in children and adolescents with chronic physical illness: a meta-analysis. Journal of Pediatric Psychology, 36, 1003-1016. doi: 10.1093/jpepsy/jsr042 
Running head: ACCEPTANCE, WELL-BEING, GOALS IN CHRONIC ILLNESS

Pinquart, M., \& Teubert, D. (2012). Academic, physical, and social functioning of children and adolescents with chronic physical illness: a meta-analysis. Journal of Pediatric Psychology, 37, 376-389. doi: 10.1093/jpepsy/jsn06

Riediger, M. (2007). Interference and facilitation among personal goals: Age-group differences and associations with well-being and behavior. In B.R. Little, K. SalmelaAro, J.-E. Nurmi, \& S.D. Philipps (Eds.), Personal project pursuit: Goals action, and human flourishing (pp. 119-143). Erlbaum.

Riediger, M. \& Freund, A.M. (2004). Interference and facilitation among personal goals: differential associations with subjective well-being and persistent goal pursuit. Personality and Social Psychology Bulletin, 30, 1511-1523. doi:

$10.1177 / 0146167204271184$

Risdon, A., Eccleston, C., Crombez, G., \& McCracken, L.M. (2003). How can we learn to live with pain? A $Q$-methodological analysis of the diverse understandings of acceptance of pain. Social Science and Medicine, 56, 375-386.

Rosenthal, R. \& Rosnow, R.L. (1991). Essentials of behavioural research: Methods and data analysis ( $2^{\text {nd }}$ e.d.). New York: McGraw-Hill.

Schwartz, L.A. \& Drotar, D. (2006). Defining the nature and impact of goals in children and adolescents with a chronic health condition: review of research and a theoretical framework. Journal of Clinical Psychology in Medical Settings, 13, 393-405. doi: 10.1007/s 10880-006-9041-8

Schwartz, L.A. \& Drotar, D. (2009). Health-related hindrance of personal goal pursuit and well-being of young adults with cystic fibrosis, pediatric cancer survivors, and peers without a history of chronic illness. Journal of Pediatric Psychology, 34, 954-965. doi: 10.1093/jpepsy/jsn144 
Running head: ACCEPTANCE, WELL-BEING, GOALS IN CHRONIC ILLNESS

Seiffge-Krenke, I. (2001). Diabetic adolescents and their families: stress, coping, and adaptation. Cambridge, UK: Cambridge University Press.

Wicksell, R.K., Melin, L., Lekander, M., \& Olsson, G.L. (2009). Evaluating the effectiveness of exposure and acceptance strategies to improve functioning and quality of life in longstanding pediatric pain - a randomized controlled trial. Pain, 141, 248-257. doi: 10.1016/j.pain.2008.11.006

Wicksell, R.K., Olsson, G.L., \& Hayes, S.C. (2011). Mediators of change in acceptance and commitment therapy for pediatric chronic pain. Pain, 152, 2792-2801. doi: 10.1016/j.pain.2011.09.003 
Table 1. Means (M), standard deviations (SD), and internal consistencies (Cronbach's $\alpha$ ) of gender, age, time since diagnosis, type of diagnosis, health status, negative life events, goalrelated self-efficacy, acceptance, goal interference, goal facilitation, acceptance, positive mood, and negative mood.

\begin{tabular}{lllllll}
\hline Variable & \multicolumn{5}{l}{ Cystic fibrosis } & \multicolumn{2}{c}{ Diabetes } & \\
& $\alpha$ & $M$ & $S D$ & $M$ & $S D$ & $t$ \\
\hline 1. Gender & - & - & - & - & - & - \\
2. Age & - & 17.65 & 2.58 & & & \\
3. Time since diagnosis & - & 16.28 & 5.83 & 8.07 & 4.46 & $-4.71^{* *}$ \\
4. Type of diagnosis & - & - & - & - & - & - \\
5. Health status & - & 2.95 & 2.55 & 3.56 & .81 & -.92 \\
6. Negative life events & - & 1.27 & 2.25 & .87 & .23 & -1.12 \\
7. GR self-efficacy & .80 & 3.15 & .07 & 2.99 & .08 & -1.38 \\
8. Acceptance & .82 & 19.68 & .66 & 18.81 & .74 & -.87 \\
9. Goal interference & - & 2.64 & 3.80 & 2.80 & 4.29 & -.47 \\
10. Goal facilitation & - & 8.16 & 6.98 & 11.48 & 6.69 & $-5.15^{* * *}$ \\
11. Positive mood & .98 & 17.62 & 4.91 & 15.35 & 4.35 & $6.51^{* *}$ \\
12. Negative mood & .90 & 2.87 & 4.85 & 4.85 & 5.30 & $-5.75^{* *}$ \\
\hline
\end{tabular}

Note: GR self-efficacy = goal-related self-efficacy

$* p<.05, * * p<.01$ 
Running head: ACCEPTANCE, WELL-BEING, GOALS IN CHRONIC ILLNESS

Table 2. Multilevel regression model for daily negative and positive mood regressed on acceptance.

\begin{tabular}{|c|c|c|c|c|c|c|}
\hline & \multicolumn{3}{|c|}{ Negative mood } & \multicolumn{3}{|c|}{$\underline{\text { Positive mood }}$} \\
\hline & Coefficient & SE & $t$ & Coefficient & SE & $t$ \\
\hline Intercept $\left(\beta_{00}\right)$ & $2.04 * *$ & $.55 * *$ & $3.68 * *$ & $17.90 * *$ & $.80 * *$ & $22.29 * *$ \\
\hline Age $\left(\beta_{02}\right)$ & .02 & .02 & .79 & -.04 & .02 & -1.93 \\
\hline Time since diagnosis $\left(\beta_{03}\right)$ & $.02 *$ & $.01 *$ & $2.71^{*}$ & -.01 & .01 & -1.30 \\
\hline Health status $\left(\beta_{05}\right)$ & -.71 & .45 & -1.60 & 1.29 & .64 & 2.01 \\
\hline Acceptance $\left(\beta_{06}\right)$ & $-.34 *$ & $.14^{*}$ & $-2.49 *$ & $.55 * *$ & $.12 * *$ & $4.73 * *$ \\
\hline
\end{tabular}

Note: $\mathrm{Y}_{\mathrm{ti}}=\beta_{00}+\beta_{01}($ gender $)+\beta_{02}($ age $)+\beta_{03}($ time since diagnosis $)+\beta_{04}($ type of diagnosis $)+\beta_{05}($ health status $)+\beta_{06}($ acceptance $)+R_{0 \mathrm{i}}+\mathrm{E}_{\mathrm{ti}}$

$* p<.05, * * p<.01$ 
Running head: ACCEPTANCE, WELL-BEING, GOALS IN CHRONIC ILLNESS

Table 3. Multilevel regression model for daily experienced goal interference and goal facilitation regressed on acceptance.

\begin{tabular}{|c|c|c|c|c|c|c|}
\hline & \multicolumn{3}{|c|}{ Goal interference } & \multicolumn{3}{|c|}{ Goal facilitation } \\
\hline & Coefficient & SE & $t$ & Coefficient & $\mathrm{SE}$ & $t$ \\
\hline Intercept $\left(\beta_{00}\right)$ & $2.89 * *$ & $.93 * *$ & $3.10^{* * *}$ & $8.19^{* *}$ & $1.96^{* *}$ & $4.18^{* *}$ \\
\hline Gender $\left(\beta_{01}\right)$ & -1.15 & 1.31 & -.88 & 3.42 & 2.29 & 1.49 \\
\hline Age $\left(\beta_{02}\right)$ & -.04 & .03 & -1.44 & -.04 & .05 & -.78 \\
\hline Time since diagnosis $\left(\beta_{03}\right)$ & .01 & .01 & 1.20 & -.01 & .02 & -.72 \\
\hline Type of diagnosis $\left(\beta_{04}\right)$ & 1.51 & 1.13 & 1.34 & -.94 & 2.58 & -.36 \\
\hline Health status $\left(\beta_{05}\right)$ & -1.20 & .78 & -1.54 & .77 & 1.26 & .61 \\
\hline Negative life events $\left(\beta_{06}\right)$ & .52 & .53 & .98 & -.93 & .84 & -1.11 \\
\hline Goal-related self-efficacy $\left(\beta_{07}\right)$ & .99 & 2.05 & .49 & -.90 & 2.83 & -.32 \\
\hline Acceptance $\left(\beta_{08}\right)$ & -.22 & .16 & -1.36 & -.51 & .39 & -1.28 \\
\hline
\end{tabular}

Note: $Y_{\mathrm{ti}}=\beta_{00}+\beta_{01}($ gender $)+\beta_{02}($ age $)+\beta_{03}($ time since diagnosis $)+\beta_{04}($ type of diagnosis $)+\beta_{05}($ health status $)+\beta_{06}($ negative life events $)+\beta_{07}($ goalrelated self-efficacy) $+\beta_{08}($ acceptance $)+r_{0 i}+e_{t i}$

$* p<.05, * * p<.01$ 
Running head: ACCEPTANCE, WELL-BEING, GOALS IN CHRONIC ILLNESS

Table 4. Multilevel regression model for daily negative and daily positive mood regressed on goal interference and facilitation.

\begin{tabular}{|c|c|c|c|c|c|c|}
\hline & \multicolumn{3}{|c|}{ Negative mood } & \multicolumn{3}{|c|}{$\underline{\text { Positive mood }}$} \\
\hline & Coefficient & SE & $t$ & Coefficient & $\mathrm{SE}$ & $t$ \\
\hline Intercept $\left(\beta_{00}\right)$ & $1.26^{*}$ & $.60 *$ & $2.11 *$ & $18.79 * *$ & $.96 * *$ & $19.59 * *$ \\
\hline Gender $\left(\beta_{01}\right)$ & 1.35 & .96 & 1.41 & -1.30 & 1.02 & -1.28 \\
\hline Age $\left(\beta_{02}\right)$ & .04 & .02 & 1.90 & $-.07 * *$ & $.02 * *$ & $-3.09 * *$ \\
\hline Time since diagnosis $\left(\beta_{03}\right)$ & $.01 *$ & .01 & 2.07 & -.00 & .01 & -.40 \\
\hline Type of diagnosis $\left(\beta_{04}\right)$ & $3.87 * *$ & $1.00 * *$ & $3.87 * *$ & $-3.49 * *$ & $1.01 * *$ & $-3.45^{* *}$ \\
\hline Health status $\left(\beta_{05}\right)$ & -.57 & .49 & -1.17 & 1.33 & .82 & 1.62 \\
\hline Goal interference $\left(\beta_{10}\right)$ & .12 & .08 & 1.52 & -.05 & .08 & -.60 \\
\hline Intercept $\left(\beta_{00}\right)$ & 1.02 & .67 & 1.51 & $19.07 * *$ & $.94 * *$ & $20.32 * *$ \\
\hline Gender $\left(\beta_{01}\right)$ & 1.10 & .88 & 1.25 & -1.50 & .96 & -1.56 \\
\hline Age $\left(\beta_{02}\right)$ & .03 & .02 & 1.72 & $-.08 * *$ & $.02 * *$ & $-3.99 * *$ \\
\hline Time since diagnosis $\left(\beta_{03}\right)$ & $.02 *$ & $.01 *$ & $2.72 *$ & -.00 & .01 & .10 \\
\hline Type of diagnosis $\left(\beta_{04}\right)$ & $4.32 * *$ & $1.03 * *$ & $4.18^{* *}$ & $-4.01 * *$ & $.80 * *$ & $-4.98 * *$ \\
\hline Health status $\left(\beta_{05}\right)$ & -.45 & .47 & -.97 & 1.36 & .79 & 1.72 \\
\hline Goal facilitation $\left(\beta_{10}\right)$ & -.10 & .11 & -.96 & .16 & .08 & 1.92 \\
\hline
\end{tabular}

Note: $\mathrm{Y}_{\mathrm{ti}}=\beta_{00}+\beta_{01}\left(\right.$ gender $\left._{\mathrm{i}}\right)+\beta_{02}\left(\right.$ age $\left._{\mathrm{i}}\right)+\beta_{03}\left(\right.$ time since diagnosis $\left._{\mathrm{i}}\right)+\beta_{04}\left(\right.$ type of diagnosis $\left._{\mathrm{i}}\right)+\beta_{05}\left(\right.$ health status $\left._{\mathrm{i}}\right)+\beta_{10}\left(\right.$ goal interference $\left._{\mathrm{ti}}\right)+\mathrm{r}_{0 \mathrm{i}}+$ $r_{1 i}\left(\right.$ goal interference $\left._{\mathrm{ti}}\right)+\mathrm{e}_{\mathrm{ti}}$ or $\mathrm{Y}_{\mathrm{ti}}=\beta_{00}+\beta_{01}\left(\right.$ gender $\left._{\mathrm{i}}\right)+\beta_{02}\left(\right.$ age $\left._{\mathrm{i}}\right)+\beta_{03}\left(\right.$ time since diagnosis $\left._{\mathrm{i}}\right)+\beta_{04}\left(\right.$ type of diagnosis $\left._{\mathrm{i}}\right)+\beta_{05}\left(\right.$ health status $\left._{\mathrm{i}}\right)+\beta_{10}($ goal facilitation $\left.{ }_{\mathrm{ti}}\right)+\mathrm{r}_{0 \mathrm{i}}+\mathrm{r}_{1 \mathrm{i}}\left(\right.$ goal facilitation $\left.{ }_{\mathrm{ti}}\right)+\mathrm{e}_{\mathrm{ti}} * p<.05$, ** $p<.01$ 


\section{Running head: ACCEPTANCE, WELL-BEING, GOALS IN CHRONIC ILLNESS}

Table 5. Time-lagged multilevel regression model for next day negative and positive mood regressed on daily goal interference and facilitation.

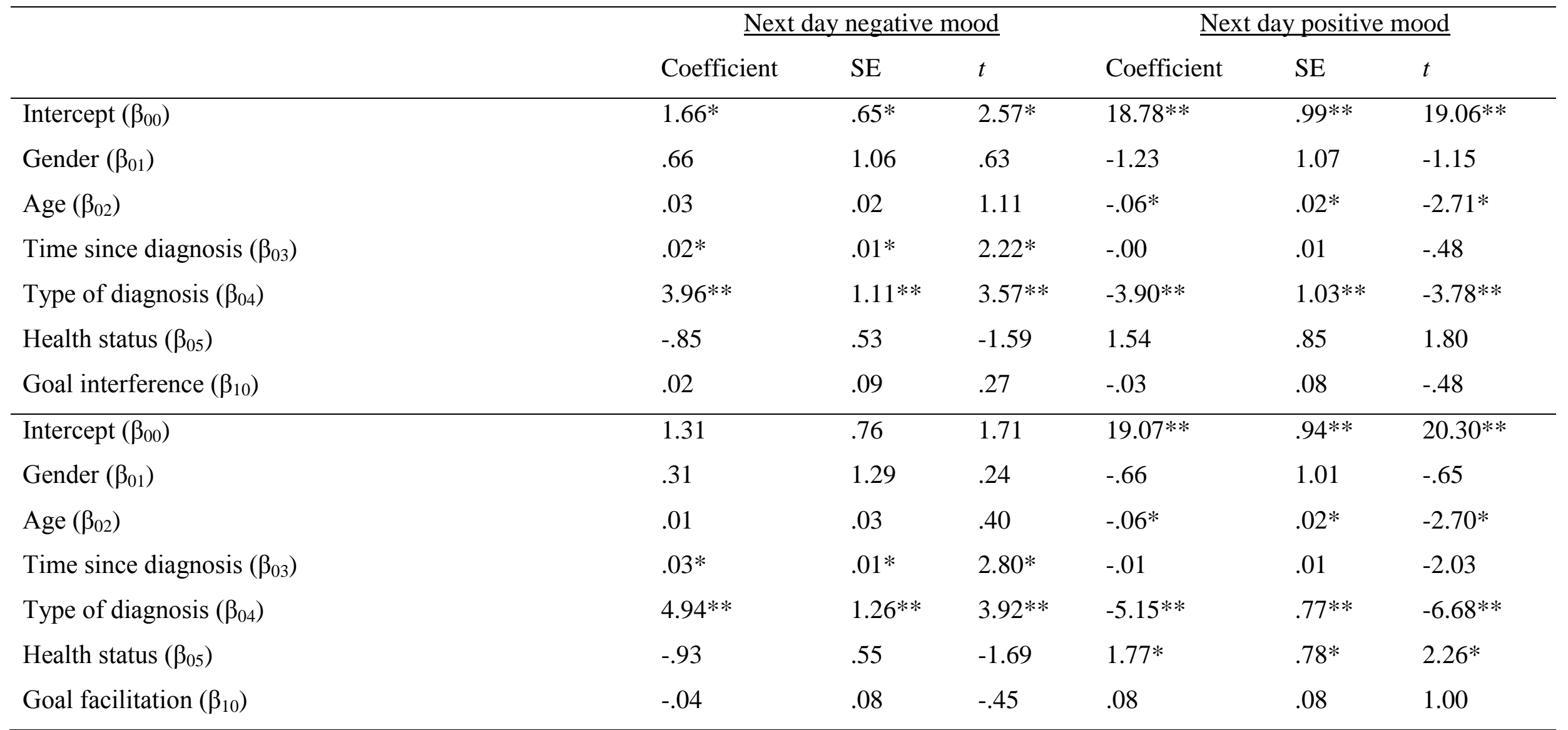

Note: $\mathrm{Y}_{\mathrm{ti}}=\beta_{00}+\beta_{01}\left(\right.$ gender $\left._{\mathrm{i}}\right)+\beta_{02}\left(\right.$ age $\left._{\mathrm{i}}\right)+\beta_{03}\left(\right.$ time since diagnosis $\left._{\mathrm{i}}\right)+\beta_{04}\left(\right.$ type of diagnosis $\left._{\mathrm{i}}\right)+\beta_{05}\left(\right.$ health status $\left._{\mathrm{i}}\right)+\beta_{10}\left(\right.$ goal interference $\left._{\mathrm{ti}}\right)+\mathrm{r}_{0 \mathrm{i}}+$ $r_{1 i}\left(\right.$ goal interference $\left._{t i}\right)+e_{t i}$ or $Y_{t i}=\beta_{00}+\beta_{01}\left(\right.$ gender $\left._{i}\right)+\beta_{02}\left(\right.$ age $\left._{i}\right)+\beta_{03}\left(\right.$ time since diagnosis $\left._{i}\right)+\beta_{04}\left(\right.$ type of diagnosis $\left._{i}\right)+\beta_{05}\left(\right.$ health status $\left._{\mathrm{i}}\right)+$ $\beta 10\left(\right.$ goal facilitation $\left.{ }_{\mathrm{ti}}\right)+\mathrm{e}_{\mathrm{ti}} * p<.05, * * p<.01$ 